Tinjauan Pustaka

\title{
ADENOMA HIPOFISIS
}

\author{
Muhammad Hidayat
}

\begin{abstract}
Abstrak
Adenoma hipofisis diklasifikasikan berdasarkan beberapa kriteria yaitu klinis dan endokrin, patologi, serta radiologi. Klasifikasi endokrin membedakan tumor sebagai fungsional dan nonfungsional, berdasarkan aktivitas sekretorinya in-vivo. Klasifikasi patologi berusaha untuk membatasi kelompok tumor heterogenus secara klinis dan patologis dengan kategori yaitu asidofilik, basofilik, dan kromofobik. Klasifikasi radiologi mengelompokkan tumor hipofisis berdasarkan ukuran dan karakteristik pertumbuhan, yang dapat ditemukan dari studi imaging. WHO membuat klasifikasi yang mencoba untuk mengintegrasikan semua klasifikasi yang ada dan menyediakan sinopsis praktis untuk aspek klinis dan patologis dari adenoma. Diagnosa adenoma hipofisis dibuat berdasarkan: gejala klinis dari gangguan hormon, adanya riwayat penyakit dahulu yang jelas, pemeriksaan fisik yang menunjang, pemeriksaan laboratorium yang menunjukkan disfungsi dari hormon yang terganggu, adanya pemeriksaan penunjang yang akurat seperti CTScan, MRI-Scan. Jenis, besar dan fungsi dari tumor sangat menentukan dalam mempertimbangkan penatalaksanaan dari adenoma hipofisis. Pengobatan diindikasikan pada semua pasien dengan gejala, terutama dengan hipogonadisme. Pilihan terapi termasuk kontrol dengan obat-obatan, reseksi bedah, dan terapi radiasi.
\end{abstract}

Kata kunci: adenoma hipofisis, patofisiologi, penatalaksanaan

\begin{abstract}
Pituitary adenomas are classified according to several criteria; clinical endocrine, pathology, and radiology. Endocrine classification distinguishes tumors as functional and nonfunctional, based on in-vivo secretory activity. Pathology classification seeks to restrict clinically heterogeneous group of tumors and pathological categories namely acidophilic, basophilic, and kromofobik. Radiological classification classifies pituitary tumors by size and growth characteristics, which can be found on imaging studies. WHO made a classification that attempts to integrate all existing classifications and provide practical synopsis for the clinical and pathological aspects of adenoma. Diagnosis of pituitary adenoma is made based on: clinical symptoms of hormonal disorders, clear past medical history, clear physical examination, laboratory tests show hormonal dysfunction or disturbance, and accurate investigations such as CT scan and MRI scan. Types, large and function of the tumor is crucial in considering the management of pituitary adenomas. Treatment is indicated in all patients with symptoms, especially with hypogonadism. Therapeutic options include control with drugs, surgical resection and radiation therapy.
\end{abstract}

Keywords: Pituitary adenoma, pathophysiology, treatment

Afiliasi Penulis : Bagian IImu Kesehatan Mata Fakultas Kedokteran Universitas Andalas/ RS. Dr. M. Djamil Padang Korespondensi: Muhammad Hidayat, Bagian IImu Kesehatan Mata Fakultas Kedokteran Universitas Andalas/ RS. Dr.

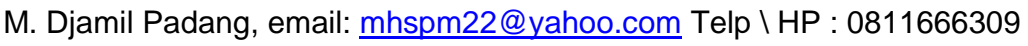




\section{PENDAHULUAN}

Adenoma hipofisis atau disebut juga dengan adenoma hipofise merupakan tumor yang jinak, dengan partumbuhan yang lambat, yang berasal dari sel-sel kelenjar hipofisis. Adenoma ini diklasifikasikan berdasarkan produk sekretorinya. Tumor fungsional (endocrine-active) termasuk hampir $70 \%$ dari tumor hipofisis yang menghasilkan 1 atau 2 hormon. Adenoma nonfungsional adalah tumor endocrine-inactive. Karena efek fisiologis dari hormon yang dikeluarkan, tumor fungsional biasanya tampak lebih awal dari pada adenoma nonfungsional. Sebaliknya, efek massa dari adenoma hipofisis yang besar (seringnya karena tumor endocrine-inactive) dapat berakibat gejala-gejala penekanan seperti sakit kepala, defek lapangan pandang (kehilangan penglihatan perifer), defisit saraf kranial, hipohipofisissme (kompresi dari kelenjar hipofisis normal), apopleksi hipofisis (perdarahan tiba-tiba atau infark perdarahan dari tumor yang meluas) atau disfungsi stalk. ${ }^{1,2}$

Pada akhir tahun 2012, diperkirakan terdapat 2800 kasus tumor sistem saraf pusat (SSP) yang didiagnosa di Kanada, dan 1850 kematian dari tumor SSP yang akan terjadi dalam periode yang sama. Adenoma hipofisis merupakan kelompok tumor yang berasal dari kelenjar hipofisis dan tercatat lebih kurang 6,6-9,1\% dari semua kanker primer SSP. 1

Tumor hipofisis adalah neoplasma intrakranial yang paling sering ditemukan. Prevalensi dari tumor ini pada laporan autopsi adalah 5-20\%. Hal menarik yang ditemukan pada saat autopsi yaitu tumor yang kecil atau mikroadenoma. Penggunaan MRI pada individu yang sehat secara tidak sengaja menemukan adenoma hipofisis. Kemajuan dalam pemeriksaan biokimia dan neeuroimaging dalam 20 tahun terakhir memfasilitasi penemuan dari tumor hipofisis dan mengubah penatalaksanaannya. ${ }^{1,3}$ Dalam makalah ini akan dibahas mengenai adenoma hipofisis, patofisiologi dan penatalaksanaannya.

\section{METODE}

Artikel ini ditulis berdasarkan hasil penelusuran dan review kepustakaan mengenai adenoma hipofisis.

\section{HASIL DAN PEMBAHASAN}

Tumor regio sellar adenoma primer hipofisis menggambarkan 10\% $25 \%$ dari neoplasma intrakranial dan adenoma menempati bagian terbesar dengan prevalensi lebih kurang $17 \%$ dan terutama terdapat pada usia 20-50 tahun. Adenoma dapat diklasifikasikan berdasarkan beberapa kriteria termasuk ukuran atau sekresi hormon, seperti sekresi hormon kortisol (penyakit Cushing) dan terapi umum yang diikuti dengan penurunan jumlah prolaktin dan volume tumor, dimana pilihan terapi pertama untuk penyakit Cushing adalah operasi. 1, 2

Adenoma hipofisis terutama timbul pada lobus anterior hipofisis, pada lobus posterior (neurohipofisis) jarang terjadi, tumor ini biasanya jinak Saat ini, penggolongan patohistologi dari adenoma hipofisis menurut kriteria WHO sangat canggih dan membutuhkan patokan yang tinggi secara metodologi. ${ }^{3}$

Kelenjar hipofisis merupakan kelenjar yang sangat penting bagi tubuh manusia, berfungsi sebagai regulator dari pelepasan hormon-hormon yang 
dihasilkan oleh hipofisis anterior maupun posterior. Kelenjar hipofisis ini terdiri dari 2 lobus, lobus anterior dan lobus posterior, pada lobus anterior kelenjar ini terdapat 5 type sel yang memproduksi 6 hormon peptida. Sedangkan pada lobus posterior dilepaskan 2 macam hormon peptida. Sekresi hormon pada adenohipofisis diatur oleh hypothalamus dan oleh umpan balik negatif dari target organ. Sedangkan pada nuerohipofisis vassopresin $(\mathrm{ADH})$ dan oxytocin diproduksi oleh hypothalamus lalu dibawa dan ditimbun untuk akhirnya dilepaskan dari hipofisis. Berbagai faktor dari hypothalamus mempengaruhi lebih dari satu tipe sel pada lobus anterior dan mempengaruhi sekresi lebih dari satu macam hormon lobus anterior, miss TRH akan merangsang produksi TSH juga merangsang pelepasan prolactin. ${ }^{3,4}$

Tumor pada kelenjar hipofisis akan memberikan gejala oleh karena adanya efek masa atau gangguan produksi hormon pada penderitanya. Evaluasi endokrin diperlukan untuk mengkonfirmasi ada atau tidak adanya suatu endokrinopathy yang akan menolong menetapkan etiologinya. ${ }^{3,4}$

Menurut klasifikasi WHO 2004, tumor hipofisis didefinisikan sebagai neoplasma yang terletak pada sela tursika. Adenoma yang berasal dari sel parenkim adenohipofisis diklasifikan sebagai adenoma tipikal dan adenoma atipikal. Pada kasus-kasus yang sangat jarang, bisa terjadi karsinoma hipofisis. Berbeda dengan adenoma tipikal, adenoma atipikal ditentukan oleh kurangnya invasi. Karsinoma hipofisis ditandai dengan adanya metastasis. ${ }^{3,4}$

Gangguan pada hipofisis dapat memiliki gambaran klinis yang bervariasi, tergantung dari jenis, besar, dan progre- sifitas tumor. Adenoma hipofisis seringkali menunjukkan gangguan yang disebabkan oleh hipofungsi atau hiperfungsi dari hormon yang dihasilkan oleh hipofisis anterior sebagai regulator diantaranya; adrenocorticotropic hormone, growth hormone, luteinizing hormone, prolactin, follicle-stimulating hormone, thyroid-stimulating hormone, antidiuretic hormone, melanocyte-stimulating hormone, oxytocin. ${ }^{3,4}$

\section{Klasifikasi Adenoma Hipofisis}

Klasifikasi lama dari tumor hipofisis didasarkan pada karakteristik selularnya menggunakan pewarnaan hematotoksilin dan eosin dari potongan jaringan. Tumor-tumor dibedakan atas eosinofilik, basofilik, atau kromofobik. ${ }^{4,5}$

Pada dasarnya, mikroadenoma mengacu pada tumor-tumor yang ukurannya $<10 \mathrm{~mm}$ dan terletak secara keseluruhan dalam sella tursika. Makroadenoma adalah tumor besar $>10$ $\mathrm{mm}$ yang bisa berada dalam intrasellar secara keseluruhan namun sering berhubungan dengan perluasan ekstrasellar. Tumor-tumor tersebut dapat meluas secara inferior ke dalam sinus sfenoid, namun lebih sering ke arah superior yaitu ke dalam ruang suprasellar (karena tahanan yang lebih rendah), menekan aparatus optik, atau secara lateral ke dalam sinus kavernosus ada sisi lainnya. ${ }^{4}, 5$ Adenoma hipofisis diklasifikasikan dalam banyak skema, hal ini termasuk klasifikasi klinis dan endokrin, patologi, dan radiologi. ${ }^{6,7}$

\section{a. Klasifikasi Klinis dan Endokrin}

Klasifikasi praktis dari adenoma hipofisis oleh dokter umum adalah kla- 
sifikasi fungsional. Klasifikasi ini membedakan tumor sebagai fungsional dan nonfungsional, berdasarkan aktivitas sekretorinya in vivo. Adenoma fungsional adalah mereka yang mensekresikan PRL, GH, TSH, atau ACTH, yang menghasilkan gambaran fenotip klinis dari sindrom amenorrhea-galaktorrhea, akromegali atau gigantisme, hipertiroid sekunder, dan penyakit Cushing atau sindroma Nelson. Tumor-tumor yang tidak berhubungan dengan keadaan hipersekretori klinis (adenoma gonadotrof, adenoma sel null, onkositomas, dan berbagai adenoma yang diam) secara kolektif didesain secara nonfungsional klinis.

Adenoma fungsional termasuk: ${ }^{4}$

1. Adenoma yang mensekresi prolaktin (PRL), umum ditemukan, terjadi pada $40-60 \%$ kasus.

2. Adenoma yang mensekresi Adrenocorticotropic Hormone (ACTH). Adenoma ini terjadi pada $5-10 \%$ adenoma hipofisis, namun $>35 \%$ pada karsinoma hipofisis; berhubungan dengan penyakit Cushing.

3. Adenoma yang mensekresi Growth Hormone (GH), terjadi pada 2-3\% kasus; dihubungkan dengan akromegali dan gigantisme.

4. Adenoma yang mensekresi Thyroid Stimulating Hormone (TSH), terjadi < $1 \%$ kasus. Berhubungan dengan hipertiroidisme.

5. Adenoma tipe campuran, mensekresikan lebih dari satu hormon; terjadi pada kira-kira $10 \%$ dari adenoma fungsional.

Adenoma non fungsional dilaporkan terjadi antara 25\% dan 35\% dari adenoma hipofisis, tidak aktif secara hormonal, dan merupakan bentuk yang lazim dari makroadenoma. Tumor hipofisis yang menghasilkan Follicle Stimulating Hormon (FSH) dan Luteinizing Hormone (LH) digolongkan ke dalam adenoma nonfungsional. ${ }^{4,5,8}$

b. Klasifikasi Patologi

Klasifikasi ini berusaha untuk membatasi kelompok tumor heterogenus secara klinis dan patologis dengan kategori yaitu asidofilik, basofilik, dan kromofobik. Diasumsikan bahwa adenoma asidofilik merupakan tumor yang mensekresikan GH dan adenoma basofilik yang mensekresikan ACTH. Tumortumor yang gagal diwarnai didesain secara kormofobik dan dipercaya sebagai tumor yang hormonnya tidak aktif. 4, 9

\section{c. Klasifikasi Imaging}

Dari pandangan surgikal, tumor hipofisis dapat diklasifikan berdasarkan ukuran dan karakteristik pertumbuhan, yang dapat ditemukan dari studi imaging. Secara praktisnya, berdasarkan ukuran, tumor diklasifikasikan sebagai mikroadenoma (diameter $<1 \mathrm{~cm}$ ), atau makroadenoma (diameter $>1 \mathrm{~cm}$ ). Namun sistem ini gagal bertahan untuk jenis-jenis dan ukuran yang dahsyat pada makroadenoma. ${ }^{5,9}$

Klasifikasi yang tetap bertahan adalah yang dietmukan oleh Hardy dan dimodifikasi oleh Wilson. Tumor diklasifikasikan atas 5, yaitu pertama tumor dibedakan atau mikroadenoma dan makroadenoma. Mikroadenoma yang menggambarkan tumor grade 0 dan grade 1 , tergantung apakan gambaran sellar normal atau perubahan sellar sedikitnya ada. Makroadenoma menyebab- 
kan perbesaran difus, destruksi fokal, dan destruksi perluasan dari sella mengarah kepada grade II, grade III, dan grade IV. Pada sistem ini, makroadenoma juga distagingkan berdasarkan derajat dan arah dari perluasan ekstrasellar, perluasan ke sistern suprasellar saja (stage A), ke lantai ventrikel ketiga (stage B), atau ke dalam ventrikel ketiga (stage C). Tumor yang meluas ke intradural lateral atau ekstradural mengarah ke stage $D$ dan stage E. 5, 7,9

\section{d. Klasifikasi WHO}

Untuk menciptakan klasifikasi komprehensif yang bisa diterima secara universal oleh dokter umum, patologis, dan surgikal, WHO mengklasifikasikan tumor ini beradasarkan tujuh, yaitu: 3, 10

1. Presentasi klinis dan aktivitas sekretori (misalnya akromegali)

2. Data neuroimaging dan intraoperatif (ukuran dan invasinya-grade Hardy)

3. Gambaran histologis (tipikal atau atipikal)

4. Profil imunohistokemikal

5. Subtipe ultrastruktur

6. Biologi olekular

7. Genetik

Klasifikasi ini mencoba untuk mengintegrasikan semua klasifikasi yang saling melengkapi dan menyediakan sinopsis praktis untuk aspek klinis dan patologis dari adenoma. ${ }^{4,11}$

\section{Patogenesis Adenoma Hipofisis}

Sampai dekade terakhir, ada dua teori yang berlaku untuk asal tumor hipofisis. Yang paling umum diterima adalah teori bahwa tumor ini merupakan kelainan intrinsik dalam kelenjar itu sen- diri. Teori lainnya disebabkan terutama oleh hipotalamus. Menurut hipotesis kedua, tumor hipofisis merupakan hasil dari stimulasi lanjutan oleh hormon atau faktor hipotalamus. Kebanyakan penulis lebih menyukai hipotesis yang lama, menganjurkan bahwa tumor hipofisis adalah primer atau timbul sebagai akibat dari kelainan intrinsik dalam kelenjar. ${ }^{6,} 12$

\section{Patofisiologi dari Manifestasi Klinis}

Gejala klinis awal dari efek endokrin dengan sekresi kelenjar hipofisis berlebihan, terutama pada prolaktin yang berlebihan menyebabkan hipogonadisme sekunder, dapat mengarahkan pada diagnosa awal dari adanya adenoma hipofisis sebelum timbul manifestasi yang lebih lambat seperti pembesaran sellar, panhipopituitarisme, dan suprasellar dengan gangguan penglihatan. Manifestasi klinis lain bisa dijumpai ialah nyeri kepala, pusing, dapat juga disorientasi tempat, gangguan penglihatan, bila tumor mendesak kiasma optikum, dan gangguan nervus lainnya, tergantung besar tumor, mikroadenoma bila tumor dengan diameter kurang dari $1 \mathrm{~cm}$, dan makroadenoma bila diameter lebih dari 1 cm. ${ }^{1,3}$

Pasien dengan tumor hipofisis menunjukkan macam-macam tanda dan gejala klinis yang dapat dibagi ke dalam kategori berikut: 1,3,5

1. Tanda dan gejala yang berhubungan dengan produksi hormon yang berlebihan. Misalnya tanda dan gejala dari hiperkortisolisme pada pasien dengan adenoma yang mensekresi ACTH atau tanda dari pasien akromegali dengan adenoma yang mensekresi $\mathrm{GH}$.

2. Tanda dan gejala yang berhubungan dengan efek mekanik dari perluasan 
tumor ke dalam sella tursika. Seperti gejala sakit kepala, gangguan penglihatan dan kelumpuhan saraf kranial.

3. Tanda dan gejala dari kelemahan fungsi hipofisis normal. Hal ini hampir selalu ditemukan pada pasien-pasien dengan makroadenoma, pengecualian utama yaitu ketika gangguan dari fungsi hipofisis yang diakibatkan oleh efek dari sekresi hormon yang berlebihan. Contoh lazim selanjutnya yaitu temuan hipogonadsisme pada pasien dengan adenoma yang mensekresi prolaktin.

\section{Diagnosa}

Diagnosa adenoma hipofisis dibuat berdasarkan: gejala klinis dari gangguan hormon, adanya riwayat penyakit dahulu yang jelas, pemeriksaan fisik yang menunjang, pemeriksaan laboratorium yang menunjukkan disfungsi dari hormon yang terganggu, adanya pemeriksaan penunjang yang akurat seperti CTScan, MRI-Scan. 3, 5, 13

Diagnosa banding yang mungkin ialah kelainan hipofisis oleh karena terapi obat-obat yang mempengaruhi kerja hormon seperti seseorang yang sedang mendapatkan terapi gonadotropin releasing hormone $(\mathrm{G} n \mathrm{RH})$ pada penderita tumor prostate akan mengalami hipogonadism hipogonadotropik yang reverseble. Pemberian kortikosteroid atau megestrol akan mengakibatkan suatu keadaan yang disebut penekanan ACTH endogenous yang reversible. Pemberian cytomel (triiodothyronine) dan juga bexarotene akan menekan sekresi TSH. Keadaan kehamilan akan menampakkan gejala hiperprolaktinemia. Kelainan hipofisis dan hipotalamus oleh karena tumor di daerah diafragma dari sella tursika, tumor pada planum spenoidale dan tuberkulum sella, contohnya meningiomas dan tumor lainnya. Lesi pada daerah hipotalamus menyebabkan hipersekresi dari prolaktin, maupun terjadinya tekanan. ${ }^{3,7,8}$

\section{Penatalaksanaan Tumor Hipofisis}

Jenis, besar dan fungsi dari tumor sangat menentukan dalam mempertimbangkan penatalaksanaan dari adenoma hipofisis. Evaluasi terpenting adalah membedakan apakah tumor ini bersifat hiposekresi atau yang hipersekresi, karena akan berpengaruh pada pemberian terapi pengganti hormon dan keputusan untuk perlunya sebuah tindakan operasi atau radiasi. Pada beberapa penderita pemberian terapi yang intensif terkadang tidak dilakukan karena akan membuat lesi yang luas pada tumor bila hendak dilakukan reseksi oleh karenanya dipertimbangkan pengobatan terhadap defisiensi hormon dengan tetap melakukan control terhadap tanda, gejala, pemeriksaan darah, dan pemantauan foto roentgen serial. ${ }^{3,}$ 14,15

Tatalaksana untuk tumor hipofisis harus secara komprehensif dan individual, dengan tujuan. ${ }^{3,6}$

1. Mengawasi tanda klinis dan biokimia dari sekresi hormon yang berlebihan.

2. Pemeliharaan fungsi normal hipofisis sedapat mungkin.

3. Menatalaksana kelemahan fungsi hipofisis.

4. Mengawasi pertumbuhan tumor dan efek mekanis pada struktur sekitarnya.

Pada pusat kesehatan yang telah berpengalaman, tujuan tersebut dapat dicapai pada banyak pasien dengan mikroade- 
noma hipofisis melalui tatalaksana medis ataupun operasi. Beberapa modalitas juga penting untuk pasien, khususnya pada mereka dengan adenoma besar yang tidak invasif. Keberhasilan pengobatan tergantung pada derajat invasi tumor, ukuran dan perluasannya. ${ }^{4,16}$

\section{a. Tatalaksana Surgikal}

Pendekatan yang utama, operasi adenomektomi transsfenoidal, sangat efektf, dengan rendahnya angka morbiditas dan mortalitas. Fungsi hipofisis normal biasanya terjaga dan biasanya terdapat kesembuhan dari fungsi yang hilang. Kraniotomi selanjutnya penting pada beberapa pasien dengan gejala sisa, tumor suprasellar yang tidak berkurang selama pendekatan transsphenoidal. Pengobatan dengan operasi menghasilkan perbaikan pada gejala penglihatan sekurang-kurangnya 70$80 \%$ pada pasien-pasien dengan kompresi kiasma preoperatif. ${ }^{6,16}$

Pengangkatan tumor secara keseluruhan sebenarnya dapat dicapai, namun tidak pada semua pasien. Hasil dari operasi tersebut ditentukan oleh pengalaman operator, ukurna adenoma, dan derajat perluasannya ke sella tursika. Perluasan tumor ke dalam sinus kavernosus selalu dihubungkan dengan pengangkatan yang tidak komplit. Rekurensi dari adenoma hipofisis setelah pengangkatan komplit dilaporkan terjadi pada $10-25 \%$ pasien, biasanya terjadi pada 4 tahun pertama. ${ }^{16-18}$

\section{b. Terapi Radiasi}

Terapi radiasi merupakan sebuah pilihan yang dianjurkan, untuk beberapa alasan. Pada studi yang lebih dulu, tera- pi radiasi direkomendasikan sebagai pengobatan primer untuk semua jenis tumor hipofisis, khususnya pada pasienpasien yang memiliki faktor risiko buruk untuk operasi. Penggunaan terapi radiasi sudah dikurangi, karena catatan utama adanya teknik neurosurgika dan kemampuan bentuk lain dari tatalaksana medis untuk tipe-tipe adenoma. 9,13

Saat ini, terapi radiasi jarang direkomendasikan sebagai terapi primer. Bagaimanapun juga, penggunaannya sebagai terapi adjuvan pada pasien-pasien dengan adenoma fungsional ataupun nonfungsional. Setiap usahan harus dibuat untuk meniadakan kiasma optik dari irradiasi. ${ }^{11,} 18$

Terdapat komplikasi yang disebabkan terapi radiasi, dan beberapa di antaranya cukup serius. Salah satu dari komplikasi yang serius terlihat pada beberapa pasien, dalam waktu yang singkat terdapat gejala penurunan penglihatan sekunder karena edem, perdarahan tumor dan nekrosis saraf optik. Komplikasi lainnya termasuk peningkatan risiko dari tumor otak yang berkembang menjadi malignant, nekrosis otak, dan demensia. Kehilangan progresif dari fungsi hipofisis adalah komplikasi kronik dari terapi radiasi. Diperkirakan bahwa, setelah follow up selama 10 tahun, lebih dari $90 \%$ pasien mengalami sedikitnya dua atau lebih defisiensi hormon. 6, 9

\section{Indikasi Pengobatan}

Pengobatan diindikasikan pada semua pasien dengan gejala, terutama dengan hipogonadisme. Pasien-pasien yang tidak ada tanda dan gejala berhubungan dengan tumor atau hiperprolaktinemia tidak membutuhkan pengobatan kecuali adenomanya berukuran be- 
sar. Pilihan terapi termasuk kontrol dengan obat-obatan, reseksi bedah, dan terapi radiasi. Masing-masing modalitas pengobatan ini telah dinilai pada berbagai penelitian komprehensif. Faktor-faktor seperti ukuran tumor, tingkat hiperprolaktinemia, manifestasi klinis, dan preferensi pasien akan mempengaruhi dalam menentukan jenis terapi yang akan diberikan. ${ }^{6,9}$

\section{Keganasan pada Adenoma Hipofisis}

Tumor hipofisis bisa menunjukkan perilaku keganasan melalui invasi, proliferasi, atau metastasis. Perilaku invasif, pada invasi dural, yang menyebabkan perluasan tumor ke dalam daerah suprasellar, sinus sphenoid, atau sinus kavernosus, adalah hal yang biasa ditemui. Insidens invasi dural pada tumor hipofisis dilaporkan pada $40 \%$ pasienpasien Mayo Clinic. ${ }^{16,17}$

Tumor hipofisis biasanya dianggap jinak dan merupakan lesi terbatas, tumbuhnya lambat, sehingga insidensi dengan fenomena keganasan mengejutkan banyak pihak. Oleh karena itu, tumor hipofisis berlaku seperti meningioma, yang dapat menginvasi dura dan tulang lebih mudah daripada otak. ${ }^{16}$

Bentuk lazim dari invasi yang mempengaruhi lantai sella tursika. Dengan membesarnya tumor, tonjolan

\section{DAFTAR RUJUKAN}

1. Arafah BM, Nasrallah MP. Pituitary Tumors: Pathophysiology, Clinical Manifestations and Management. Endocrine-related cancer. 2001;8(4):287-305.

2. Becker G, Kocher M, Kortmann RD, Paulsen $F$, Jeremic B, Muller RP, et al. Radiation tulang sella akan terkikis dan terlihat lebih tipis dari radiografi lateral tengkorak atau MRI. Hilangnya prosessus klinoid dan adanya bentuk "double floor" merupakan pertimbangan patognomonis untuk tumor intersellar. Sejalan dengan pembesaran dan perluasan tumor ke dalam sisterna supprasellar, diafragma akan membengkak ke atas dan meregang. Kebanyakan kasus suprasellar ini dapat mengarah ke midline dan kasus beratnya akan mengisi ventrikel ketiga dan menyebabkan hidrosefalus. ${ }^{12,18}$

\section{SIMPULAN}

Tumor hipofisis bersifat ganas bila menghasilkan hormon yang berlebihan dan dapat menyebabkan kematian pada pasien; bila menginvasi atau menekan struktur parasellar, terutama jalur visual; atau bila terjadi perdarahan atau metastasis. Tumor hipofisis saat ini banyak terdeteksi oleh pemeriksaan MRI dan biokimia sebelum mencapai ukuran yang akan menyebabkan gejala. Meskipun penggolongan umum dari tumor ini menurut produksi hormon sudah dilakukan dalam 15 tahun, patogenesisnya masih belum bisa dimengerti. Pendekatan medis, operasi, dan radiobiologi untuk pengobatan lesi sudah ditemukan, namun sejumlah kasus belum dapat disembuhkan.
Therapy in the Multimodal Treatment Approach of Pituitary Adenoma. Strahlentherapie und Onkologie : Organ der Deutschen Rontgengesellschaft [et al]. 2002;178(4):173-86. 
3. Chanson P, Salenave S. Diagnosis and Treatment of Pituitary Adenomas. Minerva endocrinologica. 2004;29(4):241-75.

4. Kontogeorgos G. Classification and Pathology of Pituitary Tumors. Endocrine. 2005;28 (1):27-35.

5. Edal AL. [Radiological Classification of Pituitary Adenomas]. Ugeskrift for laeger. 2001;163(33):4349-53.

6. Levy A. Pituitary Disease: Presentation, Diagnosis, and Management. Journal of neurology, neurosurgery, and psychiatry. 2004;75 Suppl 3:iii47-52.

7. Ho RW, Huang HM, Ho JT. The Influence of Pituitary Adenoma Size on Vision and Visual Outcomes after Trans-Sphenoidal Adenectomy: A Report of 78 Cases. Journal of Korean Neurosurgical Society. 2015;57(1):2331.

8. Oruckaptan HH, Senmevsim O, Ozcan OE, Ozgen T. Pituitary Adenomas: Results of 684 Surgically Treated Patients and Review of the Literature. Surgical neurology. 2000;53(3): 211-9.

9. Yildiz F, Zorlu F, Erbas T, Atahan L. Radiotherapy in the Management of Giant Pituitary Adenomas. Radiotherapy and oncology : journal of the European Society for Therapeutic Radiology and Oncology. 1999; 52(3):233-7.

10. Ozgen T, Oruckaptan HH, Ozcan OE, Acikgoz B. Prolactin Secreting Pituitary Adenomas: Analysis of 429 Surgically Treated Patients, Effect of Adjuvant Treatment
Modalities and Review of the Literature. Acta neurochirurgica. 1999; 141(12):1287-94.

11. Mortini P, Barzaghi R, Losa M, Boari N, Giovanelli M. Surgical Treatment of Giant Pituitary Adenomas: Strategies and Results in a Series of 95 Consecutive Patients. Neurosurgery. 2007;60(6):993-1002; discussion 3-4.

12. Soule SG, Jacobs HS. The Evaluation and Management of Subclinical Pituitary Disease. Postgraduate medical journal. 1996;72(847): 258-62.

13. Vance ML. Treatment of Patients with a Pituitary Adenoma: One Clinician's Experience. Neurosurgical focus. 2004;16(4):E1.

14.Wang S, Lin S, Wei L, Zhao L, Huang Y. Analysis of Operative Efficacy for Giant Pituitary Adenoma. BMC surgery. 2014;14:59.

15.Egger J, Kapur T, Nimsky C, Kikinis R. Pituitary Adenoma Volumetry with 3d Slicer. PloS one. 2012;7(12):e51788.

16. Mezosi E, Nemes O. [Treatment of Pituitary Adenomas]. Orvosi hetilap. 2009;150(39): 1803-10.

17.Musluman AM, Cansever T, Yilmaz A, Kanat $A$, Oba E, Cavusoglu $H$, et al. Surgical Results of Large and Giant Pituitary Adenomas with Special Con-sideration of Ophthalmologic Outcomes. World neurosurgery. 2011;76(1-2):141-8; discussion 63-6.

18.Schaffler A. [Treatment of Pituitary Gland Hyperfunction: From Acromegaly to Prolactinoma]. Der Internist. 2006;47 (12): 1215-6, 8-20, 22. 